Revista do CESP, Belo Horizonte, v.36, n.55, p. 11-27, 2016

\title{
Os muitos desassossegos
}

\section{The several unquietnesses}

Jerónimo Pizarro

Universidad de los Andes, Bogotá / Colômbia

jeronimopizarro@gmail.com

Resumo: O presente artigo tem por objetivo discutir a problemática existente em torno das várias versões que constituem o Livro do Desassossego, obra proteiforme do poeta português Fernando Pessoa.

Palavras-chave: Fernando Pessoa; Livro do desassossego; poesia portuguesa.

Abstract: This article aims to discuss the topic regarding the several versions of which $O$ livro do desassossego is consisted, a protean work by the Portuguese poet Fernando Pessoa

Keywords: Fernando Pessoa; Book of disquiet; Portuguese poetry.

Data de recebimento: 14 de setembro de 2015

Data de aprovação: 16 de outubro de 2015

Nas páginas seguintes gostaria de me ocupar novamente da questão dos muitos desassossegos, isto é, da existência de um livro plural que é muitos Livro do Desassossego, visto que do Desassossego temos menos um livro do que uma realidade arquivística e que todas as tentativas de transformar essa realidade num livro único são póstumas. Significativamente, o projecto de investigação mais recente sobre o Livro 
do Desassossego, coordenado por Manuel Portela, já não passa pela tentativa de organizar novamente o Livro, mas pela construção de um arquivo digital desse livro proteico, como Pessoa, e intitula-se: "Nenhum problema tem solução". ${ }^{1}$ O que Manuel Portela sugere é algo que já outros críticos tinham afirmado antes, e talvez ninguém com tanta força quanto Leyla Perrone-Moisés num artigo de 1990: "O verdadeiro e definitivo Livro do desassossego nunca existiu, e não existirá jamais" (2001, p. 293). Mas porquê esse livro é vários livros e porquê se transformou em mais livros e porquê não existirá jamais como um único livro, "verdadeiro e definitivo"? Simplesmente, porque Pessoa foi várias "pessoas-livros" (PESSOA, 2010, tomo 1, p. 447) -Fernando Pessoa, Vicente Guedes e Bernardo Soares, no caso do Livro do Desassossego-, porque Pessoa não chegou a organizar esse todo sonhado do qual só publicou alguns trechos em vida, e porque, como consequência do anterior, o editor de Pessoa não poderá nunca organizar de um modo "verdadeiro e definitivo" o que o próprio autor não chegou a dispor numa determinada ordem. Mas é este um problema ou, utilizando uma linguagem quase técnica, um problema passível de correcção? É porventura problemático que Pessoa não tenha sido uno e que um conjunto de "trechos, bocados, excerptos do inexistente" (PESSOA, 2013b, p. 354) -palavras de difícil tradução, aliás- não possam formar um único livro? Penso que não. Penso que não é um problema, é apenas a realidade, e que, portanto, não precisa de ser solucionado nem corrigido. A meu ver, temos que nos adaptar à pluralidade literária de Fernando Pessoa da mesma forma que temos que reconhecer a pluralidade editorial dos seus livros - nomeadamente do Desassossego-, visto que não é negativo, e sim extremadamente positivo, pois é um signo de vitalidade, que Pessoa seja cada dia mais múltiplo em termos de edição e de interpretação. Todo autor está destinado a multiplicar-se (a ser multiplicado) e muito mais um que se multiplicou e deixou as suas arcas para a posteridade. Pessoa leva -e isso é bom-a abandonar uma certa nostalgia de unidade e a reconhecer que o nosso Pessoa é só "Um Fernando Pessoa", para evocar Agostinho da Silva.

Para me ocupar da questão dos muitos desassossegos, vou tentar explicitar alguns dos diferentes níveis aos quais o Livro é múltiplo.

\footnotetext{
${ }^{1}$ O título remete para a primeira linha de um trecho do Livro do Desassossego datado por Fernando Pessoa de 18-7-1916 (BNP/E3, 144D²-135r, in, PESSOA, 2013b, p. 188).
} 
Parece-me necessário esclarecer esses níveis para que se perceba bem até que ponto há muitos desassossegos e haverá muitos mais.

O primeiro que é importante frisar é que o Livro que ficou não era um Livro, com maiúscula e em singular, mas vários livros, como defenderam, entre outros, Jorge de Sena (1979) e Leyla Perrone-Moisés (2001a), e que, portanto, o que aconteceu depois da morte física de Pessoa, em 1935, não foi tanto a multiplicação do uno, como o big bang do que já era diverso à partida. O Livro do Desassossego foi inicialmente um "breviário do decadentismo" (LIND, 1983), uma série de apoteoses e de glorificações, um conjunto de litanias e de devaneios, um livro de máximas e de conselhos, um manual de maneiras de bem sonhar-com um capítulo intitulado "Educação sentimental"-, um diário íntimo de viagens nunca feitas e lúcidos exames de consciência de um solitário pelas florestas do alheamento. Este foi o primeiro Livro, de pendor pós-simbolista, com algumas passagens sensacionistas tardias, escrito pelo leitor de Henri-Frédéric Amiel, de Joris-Karl Huysmans, de Oscar Wilde, de Maurice Maeterlinck, de Mário de Sá-Carneiro, entre outros. Como Georg Rudolf Lind explica, "os textos desta primeira fase distinguem-se bastante pela artificialidade rebuscada da sua dicção póssimbolista dos textos da segunda fase, os quais tendem à simplicidade e exactidão da expressão, e isto apesar da sua proximidade com o género da poesia em prosa" (1983, p. 21). Esses textos terão sido escritos fundamentalmente entre 1913 e 1918 (embora alguns em 1919-1920), quase todos se encontram manuscritos e por volta de 1915, ou depois, iam ser unificados mediante o recurso a um autor fictício, Vicente Guedes, cujos escritos -alguns contos e poemas ostentam a assinatura de Guedes-nunca foram reunidos e editados por separado. Desde meados da década de 1910, Fernando Pessoa percebeu que a diversidade dos textos destinados ao Livro podia ser atenuada mediante a exclusão de aqueles mais dissemelhantes, mas também recorrendo a um autor, isto é, a uma forma de unidade que funcionasse como suporte da heterogeneidade. Já o diria Michel Foucault mais tarde: "O autor é ainda aquilo que permite ultrapassar as contradições que podem manifestar-se numa série de textos: deve haver -a um certo nível do seu pensamento ou do seu desejo, da sua consciência ou do seu inconsciente- um ponto a partir do qual as contradições se resolvem, os elementos incompatíveis encaixam finalmente uns nos outros ou se organizam em torno de uma contradição 
fundamental ou originária" (2000, p. 53).2 Se Pessoa tivesse publicado os trechos do Livro do Desassossego para o qual escreveu textos prefaciais por volta de 1917, talvez tivesse dado a conhecer só uma selecção deles antecedida de um texto que incluísse uma apresentação de Vicente Guedes. Mas esse livro nunca chegou a existir.

De facto, passou quase uma década e por volta de 1929 Pessoa retomou o Livro. O novo livro tinha, por assim dizer, uma nova personagem: a cidade de Lisboa (daí uma frase famosa: "Oh, Lisboa, meu lar!"’3); tinha um novo empregado de escritório: Bernardo Soares, que era conhecido entre os colegas - tinha-os!- como o "Sr. Soares"; tinha paisagens mais reais, isto é, com menos cisnes, lírios, ciprestes, palácios e príncipes, e mais praças, largos, jardins, varinas e eléctricos. Os trechos deste livro já não tinham títulos "grandiosos" (PESSOA, 2013b, p. 528), terão sido escritos entre 1929 e 1934, quase todos se encontram dactilografados (alguns até são cópias a químico de originais enviados para uma revista), têm anotações nas margens como se de provas tipográficas se tratasse e iam ser assumidos por um segundo autor fictício, Bernardo Soares, cujos escritos -alguns contos estão atribuídos a Soares- ainda não foram publicados por separado. Por volta de $1930 \mathrm{o}$ artifício teria sido o mesmo de 1915: dar unidade a uma multiplicidade de trechos optando por um único autor; com a diferença de que os textos da segunda fase do Livro do Desassossego são mais homogéneos e referem muito mais o local de trabalho do semi-heterónimo Soares. Por isso, o maior desafio de Fernando Pessoa no início da década de 1930 não terá sido a selecção dos textos tardios -muitíssimos deles revistosmas a falta de harmonia destes com os mais antigos. Numa nota datável de 1931, Pessoa considera necessário dotar de unidade psicológica e estilística ao Livro; para este fim, pondera adaptar os trechos antigos à "vera psychologia" (2013b, p. 527) de Bernardo Soares, menos dandy do que Vicente Guedes, e leitor, como este, de Stéphane Mallarmé,

\footnotetext{
2 "L'auteur, c'est encore ce qui permet de surmonter les contradictions qui peuvent se déployer dans une série de textes : il doit bien y avoir -à un certain niveau de sa pensée ou de son désir, de sa conscience ou de son inconscient- un point à partir duquel les contradictions se résolvent, les éléments incompatibles s'enchainant finalement les uns aux autres ou s'organisant autour d'une contradiction fondamentale ou originaire" (FOUCAULT, 1969, p. 85).

${ }^{3} \mathrm{Cf}$. "Que humano era o toque metallico dos electricos! Que paysagem alegre a simples chuva na rua ressuscitada do abysmo! || Oh, Lisboa, meu lar!”(PESSOA, 2013b, p. 322).
} 
mas também do Padre António Vieira e dos retóricos do século XVIII; e projecta "fazer uma revisão geral do proprio estylo" (2013b, p. 527), mantendo uma característica expressiva comum a todos os trechos do Livro, quer antigos, quer recentes: "o devaneio e o desconnexo logico" (2013b, p. 527). Mas mesmo adaptando uns trechos à psicologia de Soares e revendo o estilo de todos os selecionados, ficava o problema de onde inserir ou para onde transferir aqueles que tinham títulos "grandiosos" (2013b, p. 528). Pessoa duvidava entre incluir ou excluir, por exemplo, trechos como "Marcha Funebre do Rei ${ }^{4}$ Luiz Segundo da Baviera" e "Symphonia de uma Noite Inquieta" (2013, p. 528). Perante as dúvidas que o autor nunca resolveu, a minha posição tem sido muito simples: se nós não quisermos suplantar Pessoa, quer adaptando, revendo, inserindo ou transferindo trechos, o mais simples é não misturar os antigos com os recentes, tentando rasurar as diferenças, e não excluir os classificáveis sob títulos grandiosos, procurando criar um livro autónomo com eles. Já lamentava Georg Rudolf Lind que Pessoa não tivesse tido tempo para proceder a reformulação psicológica e estilística que projectou nessa nota de 1931, e que Jacinto do Prado Coelho tivesse misturado os textos da primeira fase com os da última fase, aumentando, assim, "a grande confusão que esta colecção de materiais produz no leitor inocente" (1983, p. 22). Para mim o leitor, para além da inocência da sua leitura, deve poder contextualizar os trechos do Livro do Desassossego, para perceber até que ponto por volta de 1928-1929 toma forma uma nova proposta estética que fez possível retomar uma obra abandonada.

${ }^{4}$ Também existe a variante: “Marcha Funebre para o Rei...” (PESSOA, 2013b, p. 181). 


\section{I. do D. \\ li: \\ (nota)}

A organização do livro deve basear-se numa escolha, rigida quanto possivel, dos trechos variadamente existentes, adaptando, portm, os mais antigos, que falhen i psychologia de B.S., tal como agora surge, a essa vera psychologia. Aparte 1sso, ha que fazer una revieão geral do proprio estylo, sem que clle perca, na expressão intima, o dovanelo e o desconnexo logico que o characterizam.

Ha que estudar o caso de se se devem inserir trechos grandes, classifioaveis sob titulos grandiosos, como a Narcha Funebre do Rei Tuiz Segundo da. Baviera, ou a Symphonia de uma Noite Inquieta.

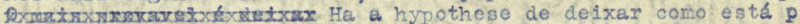
trecho da Narcha Funebre, e ha a hypothese de a transferir para outro livro, em que ficassem os Grandes Trechos juntos.

Somos morte. Isto, que consideramos vida, 6 o somno da vida real, a morte do que verdadeiramente somos. Os mortos nascem, não morrem. Estão trocados, para nós, os mundos. Quando Julgamos que vivemos, estamos mortos; vamos viver quando estamos moribundos.

Aquella relação que pa entre o somno e a vida l a mesma quo ha entre 0 que chamamos sobffir o o que chamamos morte. Estamos dormindo, e esta vida é um sonho, näo num sentido metaphorico ou.

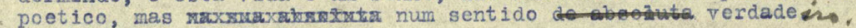

- para fixar a morte,

Tudo aquillo que em nossas actividadeg sonsjderamos superior, tudo isso participa da morte, tudo isso nisgamaxtinta. Que $f \circ$ ideal senão a confissão de que a vida não serve? que $b$ a arte senão a negação da vida? Uma estatua $e$ un corpo morto, talhado/em materia

de in- 0 mesmo prazer, que tanto parece una immersẽo na vida, $b$ antes

corrup- uma immersão em nós mesmos, uma destruição das relaçöes entre nós ção, e a vida, uma sombra agitada da morte.

\section{0 proprio viver e morrer, porque não temos uma dia a mais} na nossa xprnxvida que não tenixãs terhamos, nisso, urn dia a menos nella.

Povoamos sonhos, somos sombras errarido atravez de florestas impossiveis, em que as arvores são casas, costumes, idéas, ideacs e philosophias.

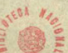

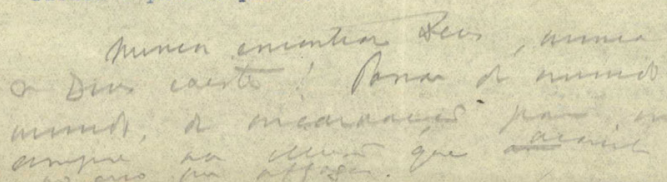

Fig. 1. BNP/E3, 2-60r. Um trecho da segunda fase do Livro do Desassossego escrito depois da nota de 1931 sobre a organização do livro.

Mas nesta ocasião interessa-me menos argumentar a favor ou contra de um determinado Livro, do que explicitar, como já disse, alguns dos diferentes níveis aos quais o Livro do Desassossego é múltiplo. 
O segundo que convém realçar é que o Livro, que devia ter um título "mais ou menos equivalente a dizer que contém lixo ou intervallo" (2013b, p. 527), e que até certo podia funcionar como um caixote de "lixo-luxo" (PERRONE-MOISÉS, 2001b) ou um cesto de intervalos lúcidos, é atribuído a figuras semi-heterónimas, primeiro Vicente Guedes e depois Bernardo Soares, que nem são Fernando Pessoa nem os seus heterónimos, o que implica que podem ser tudo o que Fernando Soares era e não era (queria dizer Fernando Pessoa, o problema é que só se distinguem por uma letra, pois Soapes seria anagrama de Pessoa). De facto, já foi defendido que o Livro do Desassossego representa uma síntese progressiva da obra pessoana e um microcosmo da multiplicidade desse universo textual.

Numa das primeiras comunicações dedicadas ao Livro, Maria da Glória Padrão (1977) -que tinha lido os textos incluídos por Maria Aliete Galhoz na introdução de Obra Poética (1960) e por Petrus na antologia Livro do Desassossego (1961)- deu numerosos exemplos do que denominou migrações de textos. Assim, por exemplo, lembrou que num trecho de 1931 se lê: "muito mais longe está o homem superior (um Kant ou um Goethe, creio que diz [Haeckel]) do homem vulgar que o homem vulgar do macaco" (2013b, p. 411); e que num poema contemporâneo de Álvaro de Campos se encontram estes versos: "A capacidade de pensar o que sinto, que me distingue do homem vulgar | Mais do que elle se distingue do macaco. | (Sim, amanhã o homem vulgar talvez me leia e comprehenda a substancia do meu ser, | Sim, admitto-o, | Mas o macaco já hoje sabe lêr o homem vulgar e lhe comprehende a substancia do ser.)" (PESSOA, 1990, p. 268). Também evocou o poema "Tabacaria" (composto em 1928; publicado em 1933), que começa: "Não sou nada. | Nunca serei nada. | Não posso querer ser nada.” (PESSOA, 1990, p. 196), e citou um trecho de 1931, em que existe esta frase: "não pertenço a nada, não desejo nada, não sou nada" (2013b, p. 405). Simples coincidências e paralelismos? Não, antes indícios de um fenómeno mais profundo que perturbou a vários críticos pessoanos, entre eles Leyla Perrone-Moisés e Eduardo Lourenço.

Num artigo publicado na revista Persona em 1983, pouco depois de publicado Fernando Pessoa, Aquém do Eu, Além do Outro (1982), e reagindo à primeira edição do Livro do Desassossego (1982) -esclareçase que Petrus, em 1961, só tinha republicado alguns trechos já aparecidos em revistas-, Perrone-Moisés constata que "ao longo dessas páginas, 
encontramos passagens em que soam, inconfundíveis, as vozes de Álvaro de Campos, Alberto Caeiro ou de Ricardo Reis. A mais recorrente é a de Álvaro de Campos: em seu quarto andar, Bernardo Soares percorre os mesmos sítios da viagem num quarto que é "Tabacaria". Mas o sorriso anti-metafísico de Caeiro também aparece em várias páginas, assim como o epicurismo triste e altivo de Reis [...] O mais curioso, a esse respeito, é o projeto explícito da heteronímia, assumido por Bernardo Soares. Num fragmento de 1930, ele resolve pôr no papel a descrição de um ideal; e esse ideal é "Sentir tudo de todas as maneiras". ${ }^{5}$ O que é aí espantoso é a qualificação de "ideal" para um projeto há muito realizado na poesia pessoana, e expresso muitos anos antes por Álvaro de Campos, com as mesmas palavras [nota: "Passagem das Horas", 1916]" (PERRONE-MOISÉS, 2001b, p. 215-216). ${ }^{6}$ E poucas linhas mais abaixo, a crítica brasileira acrescenta: "O fragmento designado como "Chapter on Indifference or something like that" propõe três maneiras de "viver a vida em Extremo". Essas três maneiras são: 1) "a posse extrema dela, pela viagem ulisséia através de todas as sensações, através de todas as formas de energia exteriorizada"; 2) "a abdicação inteira"; 3) "o caminho do perfeito equilíbrio". Essas três maneiras não corresponderiam exatamente e respectivamente às de Álvaro de Campos, de Ricardo Reis e de Alberto Caeiro?" (PERRONE-MOISÉS, 2001b, p. 216). Sem dúvida, no Livro do Desassossego Pessoa estava a integrar parcialmente uma grande parte do seu universo ficcional.

\footnotetext{
${ }^{5}$ Em Pessoa, 1982, tomo I, p.31 e Pessoa, 2013b, p. 294.

${ }^{6} \mathrm{Na}$ realidade, sendo o trecho datável de 1916, Pessoa manifesta o mesmo ideal no Livro do Desassossego e na poesia de Álvaro de Campos em 1916.

${ }^{7}$ Em Pessoa, 1982, tomo II, p.39 e Pessoa, 2013b, p. 175.
} 
Livro do Desassocego.

(Chapter on Indifference or something like that)

Toda a alma digna de si-propria deseja viver a vida em Extremo. Contenter-se com que o que the dã.o é proprio dos escravos. Pedir mais es proprio das creakcas. Conquistar mais é proprio dos loucos, porque toda a conquista $\dot{s} \ldots \ldots \ldots$.

Viver a vida em Wxtremo significa vivel-a até ao limite, mas ha trez maneiras de o fezer, o a cada alm elevada compete esoolher una das meneiras. Pode viver-se a vida em extremo pela posse extrema áelia, pela viagem ulysséa atravez de todas as serisacões vivla das, atravez de todas as fórmas da energia exteriorisada. Raros, porém, são, en tdas as epochas do mundo, os que podem fechar os olhos cheios do cansaco somma de todos os cansaços, os que possuiram tudo do todes as maneiras. Raros podem assim exigix da vida, conseguindo-o, que ella se Thes entrogue corpo e alma; sabendo não ser ciumentos a'elia por saber ter-line o anor inteiramente. Mlas este deve ser, sem duvida, o desejo de toda a alna elevada e forte. Qunano esse álma, porém, verifioe que The impossivel tal realizaç̃o, que não tem fôrças para a

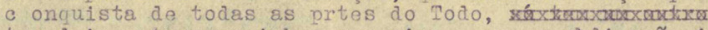
tem dois outros caminhos que siga - um, a abdicação inteira, a absteneẼo fornal, completa, relegando pare a esphera da sensibilidade aquillo que não pode possuir integralmente na região da actividade o da energia. Mris vale supremamente não agit que agir intilnente, fragmentariamente, imbastanteinente, como a innumera superflua maioria inane dos homens; outro, o caninho do perfeito equilibrio, a busca do limite na Proporção absoluta, por onāe a ansia de Extremo passa de vontade e da emocão para a Intelligencia, sendo toda a ambição não de viver toda a vida, não de sentir toda a vida, mas de ordenar toda a vida, de a cumprir em Harmonia o Coordenação intelligente.

A ansia de comprehender, oue para tantas almas nobres substitue a de agir, pertence á sphera da sensibilidade. Substituir a Intelifencia é onergia, quebrar o élo entre a vontade $\theta$ a emoção, despindo de interesse todos os gestos da vida material, eis o que, conseguido, vale nais que a vida, tão difficil de possuir completa, o tão triste de possuir daraiel.

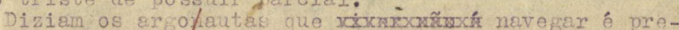
ciso, mas que viver não é preciso. Argonautas, nós, da sensibilidade doentia, disamos cue sentir á preoiso, mes que nẽo á preciso viver.

Fig. 2. BNP/E3, 7-20r. Um trecho da primeira fase do Livro do Desassossego, datável de 1916, e contemporâneo do poema "Passagem das Horas", 1916.

Foi este aspecto o mesmo que impressionou Eduardo Lourenço, numa comunicação apresentada em 1984, em Nashville, no 2. ${ }^{\circ}$ Congresso 
Internacional Pessoano. ${ }^{8}$ Essa comunicação intitulava-se "O Livro do Desassossego, texto suicida?" e nela Lourenço afirmava, tal como Perrone-Moisés, que: "O Livro comporta todos os textos de Fernando Pessoa, todas as suas mais características tonalidades desde o ultrasimbolismo sonambúlico dos jovens anos até ao simbolismo (ultra também ou menos ultra) de fim de percurso e vida. [...] [O Livro é um] texto onde dialogam indistintamente os fantasmas bem presentes de Caeiro, Reis e sobretudo de Campos, mas igualmente o do nunca sepulto autor da "Floresta do Alheamento" que aqui, em sumptuoso "requiem" à memória do wagneriano Luís II, nos aparece como Fernando, rei da nossa Baviera de sonho" (LOURENÇO, 1993, p. 89). Assim reiterava algo que já tinha dito pouco antes: "Na realidade, são as mesmas intuições capitais, as mesmas imagens, os mesmos sintagmas, as mesmas metáforas, mas ditas, assumidas em nome de outro sujeito, onde se escuta a voz de todos os outros, Caeiro, Campos, Reis, separadas ou amalgamadas, mas também banalizadas, à medida exacta de um enunciador que não tem projecto de existência como, a seu modo, o têm, por vontade expressa de Pessoa, não só Caeiro, Campos e Reis como o autor ortónimo envolvido no seu diálogo de sonho com o mundo e a vida um enunciador que não tem projecto de existência" (1993, p. 86). O Livro do Desassossego não tinha, segundo Eduardo Lourenço, um enunciador com "projecto de existência" -ou só parcial, inconsistente ou passageiramente o teve- e daí uma importante distinção como a que conclui a sua comunicação: "[...] aos textos-diferentes que justificariam a mitologia heteronímica, [...] opõe-se o texto-das-diferenças, chamado o Livro do Desassossego, onde os escritos imaginários que designamos como Caeiro, Reis e Campos se articulam entre si e [com] os outros textos não-heteronímicos" (1993, p. 95). Na obra pessoana existiriam os textos distintivos ou diferenciais -nomeadamente os dos heterónimos-e os textos suicidas ou não isolados mediante a criação de um enunciador específico e de um estilo, entre os quais o Livro do Desassossego teria um lugar destacado. Daí esta polémica observação, visto que não está isenta de uma interpretação psicológica: “[...] o que o Livro do Desassossego nos traz é, de certo modo, sendo o mesmo [Pessoa], uma diferente versão dele. É a sua versão em prosa, [...] Em prosa significa, segundo a indicação explícita do próprio

\footnotetext{
${ }^{8}$ Esse Congresso não foi o $2 .^{\circ}$, mas o $3 .^{\circ}$ se tivermos presente o I Simpósio Internacional de 1977 na Brown University; ver Monteiro, 2013.
} 
Pessoa, em menos mentira, consubstancial a toda a expressão poética... [cf. "Em prosa é mais difficil de se outrar" $]$ [...] como se Fernando Pessoa, sob a mal fingida máscara de Bernardo Soares, retirasse toda a ficção às suas ficções, [...] Sem cair no poço sem fundo do psicologismo (mas como evitá-lo?), a tentação é grande de escutar nestes textos aquela voz mais rente, mais próxima do silêncio, da opacidade, do não-dito e não-dizível da existência que nós imaginamos como sendo a de Fernando Pessoa. Quer dizer, a menos mascarada, a menos ficcional de um autor que teve a obsessão de nos prevenir que para ele, ou para quem o leia, tudo é máscara. [...] É nesse sentido e só nesse - embora o seja também pelo que nele é dito- que o Livro do Desassossego é um texto-suicida. Em si, e em relação à mitologia de Pessoa, [...]" (1993, p. 86-88). Hoje não sei se ainda poderíamos considerar o Livro do Desassossego -ou melhor, só esta obra pessoana-um livro suicida, mas o que é interessante salientar é que foi a multiplicidade inerente ao Livro, a polifonia do mesmo, que fizeram possível que Lourenço o considerasse suicida, e que, no fundo, isto queria dizer que o livro tinha sido uma espécie de diário semi-ficcional de Fernando Pessoa, quer numa primeira fase, quer numa segunda. Quase um manuscrito para a posteridade, como o do Barão de Teive, com o qual o manuscrito do Desassossego tem muitas semelhanças. ${ }^{10}$

O terceiro que é importante sublinhar é que o Livro só se transformou num livro em 1982, e daí em diante numa série interminável de livros. De facto, se considerarmos as alterações de uma edição para

${ }^{9}$ Com esta frase fecha um fragmento intitulado "Ficções do Interludio", datável de 1931. Ver Pessoa, 1966, p. 106; e Pessoa, 2010, tomo I, p. 457.

${ }^{10}$ Refira-se uma página de Eu Sou Uma Antologia (2013a, p. 55) “A Bernardo Soares, Fernando Pessoa refere-se em alguns textos tardios e bastante citados. Num deles, Pessoa aproxima Soares do Barão de Teive (cf. 134) e de Alvaro de Campos (cf. 102), o que é relevante, visto existirem trechos do Livro que, temática e estilisticamente, parecem fragmentos de Teive ou poemas em prosa de Alvaro de Campos. Confrontemse, por exemplo, as passagens em que Soares fala da sua solidão e dos espíritos da sua espécie, como Jean-Jacques Rousseau (1712-1778) ou Étienne Pivert de Senancour (1770-1846), com outros em que Teive traça uma genealogia espiritual quase idêntica. Ou compare-se o texto de 27 de Junho de 1930, que termina com a exclamação "Mas quantos Cesares fui!" (3-27r), com o poema "Pecado original" (70-59r) de Campos, em que figura a mesma exclamação e outras afins". Veja-se também o prefácio de Prosa de Álvaro de Campos (2012). 
outra e as dezenas de organizações propostas dentro e fora de Portugal, considero que é possível afirmar que não há dois livros iguais, e que nem as sucessivas reedições de certas edições (em que não se distinguem as reimpressões das reedições) são idênticas.

Por comodidade e para simplificar, pode afirmar-se que todas as edições de Teresa Sobral Cunha, Richard Zenith e Jerónimo Pizarro são idênticas, mas é só por comodidade e para simplificar. Para qualquer leitor atento resultará evidente que cada edição de Teresa Sobral Cunha comporta uma profundíssima revisão. O que pode resultar menos patente é que as edições de Richard Zenith e Jerónimo Pizarro, em que os fragmentos estão numerados, têm mudado. Abster-me-ei de falar das minhas edições, embora a que preparei para a INCM (2010) e a que preparei para a Tinta-da-china (2013) sejam, de facto, diferentes: na segunda, optei por colocar alguns textos prefaciais da primeira e da segunda fases do Livro no início de cada fase (e não na sua posição cronológica) e corrigi algumas leituras. Limitar-me-ei, portanto, a comentar brevemente a edição que Zenith publicou na Assírio \& Alvim, porque a sua aparente unidade dissimula uma multiplicidade mais profunda. Digo "dissimula", porque certas características fazem pensar que essa edição é mais única do que é. Porquê? Porque em 15 anos só tem sido publicada por uma editora em Portugal, a Assírio \& Alvim; porque o número total de trechos numerados nunca foi alterado; e porque o prefácio de 1998 foi aumentado, mas nunca foi substituído. Mas o que aconteceu entre 1998 (1. ${ }^{\mathrm{a}}$ ed.) e 2012 (10. ${ }^{\mathrm{a}}$ ed.) que pudesse ter obrigado a rever a versão publicada em 1998? Primeiro, que em 2008 e em 2013 Teresa Sobral Cunha pôde publicar livremente duas edições do Livro do Desassossego que durante 1997-2005 não pôde (de facto, a Assírio \& Alvim bloqueou a saída da sua edição de 1997 e recuperou nessa data os direitos de exclusividade que tinha perdido em 1985, recuperado em 1997 e perdido novamente em 2006, passados já não cinquenta, mas setenta anos sobre a morte de Pessoa). Segundo, em 2010 apareceu a primeira edição crítica do Livro do Desassossego e essa edição pôs em causa a inclusão de muitos trechos e a leitura de muitas passagens. O que fez Zenith depois de consultar as edições referidas que propunham um novo corpus da obra e uma leitura diferente de muitos trechos? Corrigir as suas leituras, é claro, e incluir e excluir fragmentos; o que é surpreendente é que o fez, quase dissimuladamente, sem nunca alterar a numeração dos trechos. Quando perdia um trecho procurava um outro para preencher o 
lugar; quando ganhava um trecho excluía um que tinha incluído apesar das dúvidas relativas à sua inclusão, e, se mesmo assim, não equilibrava as contas, então fundia dois trechos em um.

Sintetizando: como a inclusão ou a exclusão de fragmentos dificilmente podia ser realizada sem alterar a numeração dos trechos, Zenith optou -nomeadamente na 8. ${ }^{\text {a }}$ edição (2009)- por efectuar "acrescentos, exclusões, deslocações e fusões" de modo a "manter a mesma numeração das edições anteriores” (PESSOA, 2009, p. 38-39). Assim, por exemplo, acrescentou dois textos diferentes para substituir sucessivamente o antigo trecho 212 (três máximas atribuídas a Álvaro de Campos), primeiro por um apontamento filosófico e depois por um texto em que se fala da morte; excluiu, passadas seis edições (1. ${ }^{\mathrm{a}}, 2$. $^{\mathrm{a}}$, 3. $.^{\mathrm{a}}, 4 .^{\mathrm{a}},{ }^{\mathrm{a}}{ }^{\mathrm{a}}$ e $6,{ }^{\mathrm{a}}$ ), as máximas de Campos, e passada uma edição (a 7..$^{\mathrm{a}}$ ), o apontamento filosófico, textos que provisoriamente formaram parte do corpus do Livro do Desassossego; deslocou o antigo trecho 123 para o final do trecho 138, porque Teresa Sobral Cunha fez notar, em 2008 (in Livro do Desassossego, 2008, p. 511-523 e 642), que o 123 era o final do 138; e portanto fusionou estes dois trechos, tal como fusionou, por exemplo, os trechos 371 e 372 (note-se que neste parágrafo refiro sempre a numeração das edições Assírio \& Alvim). Não pretendo discutir a legitimidade destas acções, sobre as quais guardo grandes reservas, mas sim considero importante sublinhar que elas existiram porque a edição de Zenith não é monolítica nem estática -embora tente ser apresentada com frequência como tal-e porque, em termos teóricos, convém reiterar que os textos não são entidades abstractas, mas entidades históricas que mudam e se transformam com o tempo, e que o sentido dos textos é inseparável da sua materialidade. A este respeito, basta confrontar as imagens referentes aos casos citados. 
212.

Ter opiniōes é estar vendido a si mesmo. Não ter opiniōes é existir. Ter todas as opiniōes é ser poeta.

213.

Tudo se me evapora. A minha vida inteira, as minhas recordaçóes, a minha imaginaçấo e o que contém, a minha personalidade, tudo se me evapora.

\section{Livro do Desassossego (1998)}

212 .

Sim o racional é real, e o real racional. Deus é um grande hegeliano'. E é-o nẩ só na obscuridade do modo como expổe o mundo, mas também na própría essência do seu pensamento-coisas.

213.

Tudo se me evapora. A minha vida inteira, as minhas recordaçốes, a minha imaginação e o que contém, a minha personalidade, tudo se me evapora. Continua-

\section{Livro do Desassossego (2007)}

212

No que somos e no que queremos somos a Morte. A Morte nos cerca e nos penetra. Vivemo-la e a isso chamamos vida.

Vivemos, dormimos e sonhamos a morte dos mortos, e morremos a da vida.

Morte é o que temos, morte o que desejamos. A nossa vida que vivemos é morte.

213.

Tudo se me evapora. A minha vida inteira, as minhas recordaçôes, a minha imaginação e o que contém, a minha personalidade, tudo se me eva-

\section{Livro do Desassossego (2012)}

Quando se sente de mais, o Tejo é Atlântico sem número, e Cacilhas outro continente, ou até outro universo.

123.

A renúncia é a libertaçấo. Năo querer é poder.

Que me pode dar a China que a minha alma me não tenha já dado? E, se a minha alma mo năo pode dar, como mo dará a China, se é com a minha alma que verei a China, se a vir? Poderei ir buscar riqueza ao Oriente, mas não riqueza de alma, porque a riqueza de minha alma sou eu, e eu estou onde estou, sem Oriente ou com ele.

\section{Livro do Desassossego (1998)}

Quem cruzou todos os mares cruzou somente a monotonia de si mesmo. Já cruzei mais mares do que todos. Já vi mais montanhas que as que há na Terra. Passei já por cidades mais que [as] existentes, e os grandes rios de nenhuns mundos fluíram, absolutos, sob os meus olhos contemplativos. Se viajasse, encontraria a cópia débil do que já vira sem viajar.

Nos países que os outros visitam, visitam-nos anónimos e peregrinos. Nos países que tenho visitado, tenho sido, nāo só o prazer escondido do viajante incógnito, mas a majestade do Rei que ali reina, e o povo cujo uso ali habita, e a história inteira daquela nação e das outras. As mesmas paisagens, as mesmas casas eu as vi porque as fui, feitas em Deus com a substância da minha imaginaçāo.

A renúncia é a libertaçāo. Nāo querer é poder.

Que me pode dar a China que a minha alma me năo tenha já dado? E, se a minha alma mo não pode dar, como mo dará a China, se é com a minha alma que verei a China, se a vir? Poderei ir buscar riqueza ao Oriente, mas não riqueza de alma, porque a riqueza de minha alma sou eu, e eu estou onde estou, sem Oriente ou com ele.

\section{Livro do Desassossego (2012)}

Fig. 3. Trechos excluídos, incluídos, deslocados e fusionados da edição de Richard Zenith do Livro do Desassossego, entre 1998 e 2012. 
Em suma, são pelo menos três os níveis aos quais o Livro do Desassossego é muitos livros. Primeiro, é muitos, porque há pelo menos dois livros identificáveis, correspondentes às duas fases de escrita da obra; a inexistência de um livro fechado e integramente revisto aquando da morte de Fernando Pessoa, em 1935, só fez mais múltiplo o que já era diverso à partida. Segundo, o Livro terá funcionado menos para a criação de uma individualidade alterna a Fernando Pessoa -como Alberto Caeiro, Álvaro de Campos e Ricardo Reis-e mais para a criação de um Fernando Pessoa semi-heterónimo em que quase todos os seus ideais (os do sensacionismo, por exemplo) e muitas das suas vozes (nomeadamente a de Campos) estão presentes. Terceiro, o Livro, depois de publicado em 1982, nunca voltou a ser o mesmo, pois nunca foi estabelecido e organizado da mesma forma por dois editores, e alguns dos editores históricos do livro, como Teresa Sobral Cunha, já fizeram mais de uma proposta de edição. De certa forma, o Livro do Desassossego simboliza as arcas pessoanas, pois os escritos guardados nessas arcas são peças de um labirinto impossível (no sentido em que Manuel Gusmão denominou o Fausto "o poema impossível" [1986]), são testemunhos de um universo polifónico e são os textos-base de um trabalho editorial que está longe de se esgotar, de atingir uma estabilidade mínima. Queríamos mais sossego crítico ou editorial? Não era em Fernando Pessoa que o íamos encontrar. De facto, a obra pessoana pode ser lida como uma realização do desassossego, isto é, como a materialização do que não nos podia tranquilizar, e por isso nem sequer a preparação demorada de uma nova edição ou de um novo livro de ensaios costuma trazer sossego. Daí que me pareça previsível que as futuras edições do Livro e os futuros estudos sobre o Livro só nos desassosseguem mais. Mas quem tem medo do desassossego?

\section{Referências bibliográficas}

GUSMÃO, Manuel . O poema impossível: O "Fausto" de Pessoa. Lisboa: Caminho, 1986.

FOUCALT, Michel. O que é um autor? 4a ed. Tradução de António Fernando Cascais e Eduardo Cordeiro; prefácio de José A. Bragança de Miranda e António Fernando Cascais. Lisboa: Vega, 2000. (Publicado em 1992 pela primeira vez). 
FOUCALT, Michel. Qu'est-ce qu'un auteur? Bulletin de la Société française de philosophie, p. 73-104, set., 1969.

LIND, Georg Rudolf. O Livro do desassossego: um breviário do decadentismo. Persona, Porto, Centro de Estudos Pessoanos / Faculdade de Letras do Porto, n. 8, p. 21-27, mar. 1983.

LOURENÇO, Eduardo. O Livro do desassossego, texto suicida? [1984]. In: _. Fernando Rei da Nossa Baviera. Lisboa: Imprensa NacionalCasa da Moeda, 1993. p. 81-95.

MONTEIRO, George. First International Symposium on Fernando Pessoa. Seven unpublished letters by Jorge de Sena. Pessoa Plural. A Journal of Fernando Pessoa Studies, n. 3, p. 113-140, Primavera 2003. Disponível em: <www.pessoaplural.com>.

PADRÃO, Maria da Glória. A escrita do desassossego [1976]. Persona, Porto, Centro de Estudos Pessoanos / Faculdade de Letras do Porto, n. 1, p. 21-31, nov. 1977.

PERRONE-MOISÉS, Leyla. O autor, "entre o escritório e a fisiologia" [1990]. In:__. Fernando Pessoa, aquém do eu, além do outro. Nova edição revista e ampliada. São Paulo: Martins Fontes, 2001a. p. 285-300.

PERRONE-MOISÉS, Leyla. O lixo/luxo de Bernardo Soares [1983]. In: . Fernando Pessoa, aquém do eu, além do outro. Nova edição revista e ampliada. São Paulo: Martins Fontes, 2001b. p. 209-221.

PESSOA, Fernando. Eu sou uma antologia: 136 autores fictícios. Edição de Jerónimo Pizarro e Patrício Ferrari. Lisboa: Tinta-da-china, 2013a. (Colecção Pessoa).

PESSOA, Fernando. Livro do Desassossego. Edição de Jerónimo Pizarro. Lisboa: Tinta-da-china. Colecção Pessoa, 2013b.

PESSOA, Fernando. Livro do Desassossego. 2a . ed. Edição de Teresa Sobral Cunha. Lisboa: Relógio d'Água, 2013c.

PESSOA, Fernando. Livro do Desassossego. 10ª ed. Edición de Richard Zenith. Lisboa: Assírio \& Alvim, 2012a.

PESSOA, Fernando. Prosa de Álvaro de Campos. Edição de Jerónimo Pizarro e Antonio Cardiello. Lisboa: Ática, 2012b. (Nova Série). 
PESSOA, Fernando. Livro do desassossego. Edição de Jerónimo Pizarro. Lisboa: Imprensa Nacional-Casa da Moeda, 2010. Edição Crítica de Fernando Pessoa, Série Maior, v. XII, 2 tomos.

PESSOA, Fernando. Livro do desassossego. $1^{\mathrm{a}}$. ed. Edição de Teresa Sobral Cunha. Lisboa: Relógio d'Água, 2008.

PESSOA, Fernando. A educação do stoico. Edição de Jerónimo Pizarro. Lisboa: Imprensa Nacional-Casa da Moeda, 2007a. Edição Crítica de Fernando Pessoa, Série Maior, v. IX.

PESSOA, Fernando. Livro do desassossego. 7ª ed. Edición de Richard Zenith. Lisboa: Assírio \& Alvim, 2007 b.

PESSOA, Fernando. Livro do desassossego. 1a. ed. Edición de Richard Zenith. Lisboa: Assírio \& Alvim, 1998.

PESSOA, Fernando. Livro do desassossego. Edição de Teresa Sobral Cunha. Lisboa: Presença, 1990-1991. 2 tomos (depósito legal do 1. ${ }^{\circ}$, 1990).

PESSOA, Fernando. Poemas de Álvaro de Campos. Edição de Cleonice Berardinelli. Lisboa: Imprensa Nacional-Casa da Moeda, 1990. Edição Crítica de Fernando Pessoa, Série Maior, v. XI.

PESSOA, Fernando. Livro do desassossego. Recolha e transcrição dos textos de Maria Aliete Galhoz e Teresa Sobral Cunha; prefácio e organização de Jacinto do Prado Coelho. Lisboa: Ática, 1982. 2 tomos.

PESSOA, Fernando. Páginas íntimas e de auto-interpretação. Edição de Georg Rudolf Lind e Jacinto do Prado Coelho. Lisboa: Ática, 1966.

PESSOA, Fernando. Livro do desassossego: páginas escolhidas. Edição de Petrus [Pedro Veiga]. Porto: Arte e Cultura, 1961.

PESSOA, Fernando. Obra poética. Edição de Maria Aliete Galhoz. Rio de Janeiro: José Aguilar, 1960.

SENA, Jorge de. Inédito de Jorge de Sena sobre o Livro do desassossego. Persona, Porto, Centro de Estudos Pessoanos / Faculdade de Letras do Porto, n. 3, p. 3-40, jul. 1979. 
